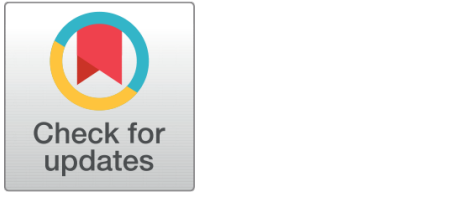

open access

Received: 07.05.2020

Accepted: 10.01 .2021

Published: 01.02.2021

Citation: Alvarez LV, Bautista AB (2021) Growth and yield performance of Pleurotus on selected Lignocellulosic wastes in the vicinity of PUP main campus, Philippines. Indian Journal of Science and Technology 14(3): 259-269. https://doi.org/ 10.17485/IJST/v14i3.389

* Corresponding author.

Ivalvarez@pup.edu.ph

Funding: PUP Institutional Fund

Competing Interests: None

Copyright: @ 2021 Alvarez \& Bautista. This is an open access article distributed under the terms of the Creative Commons Attribution License, which permits unrestricted use, distribution, and reproduction in any medium, provided the original author and source are credited.

Published By Indian Society for Education and Environment (iSee)

ISSN

Print: 0974-6846

Electronic: 0974-5645

\section{Growth and yield performance of Pleurotus on selected Lignocellulosic wastes in the vicinity of PUP main campus, Philippines}

\author{
Lourdes V Alvarez ${ }^{1 *}$, Arcibel B Bautista ${ }^{1}$ \\ 1 Department of Biology, College of Science, Polytechnic University of the Philippines, Sta. \\ Mesa, Manila, Philippines
}

\begin{abstract}
Objectives: Urban wastes that contain lignocellulosic substances are potential substrates for mushroom cultivation. The study tested selected urban wastes as substrates for the cultivation of Pleurotus djamor, P. sajor caju, and P. florida. Methods: Three different urban wastes (white used paper, banana peels and mixture of leaf litters) and their combinations were used in the study with sawdust served as the control. Percentage of mycelial growth, colonization period, and number of fruiting bodies, cap diameter, stipe length, total yield, and size of the mushroom and biological efficiency of the substrates used were assessed to determine the effects on growth and yield. Findings: Results revealed that the rapid mycelial colonization where the highest mushroom yield and percentage biological efficiency were observed from UP100 for $P$. djamor, UP75 for $P$. sajor caju and BP25 for $P$. florida and the lowest yield were obtained from those in combinations of leaf litters and banana peels. Novelty : Protocol obtained from this research can be applied and implemented in an urban setting where there are no available agricultural wastes rich in lignocellulosic substances can be used in the cultivation of edible mushroom such as $P$. djamor, P. sajor caju and P. florida.
\end{abstract}

Keywords: Oyster mushroom; growth performance; lignocellulose; biological efficiency; mushroom yield

\section{Introduction}

Mushroom contains ample amount of proteins, vitamins, minerals, dietary fiber and variety of secondary metabolites ${ }^{(1)}$ and are receiving significant attention due to their exceptional medicinal value; curative and prophylactic especially in many diseases such as high blood pressure, asthma, respiratory tracts infection, anemia, hepatitis, cancer, tumor, and many others ${ }^{(2)}$.

Growing mushrooms in the Philippines is economically feasible. Its high market demand presumes to be profitable to the mushroom growers. The large number of agricultural wastes and warm climatic conditions in the country provide tremendous opportunity for mushroom cultivation. Generally, mushrooms are grown on 
pasteurized agricultural wastes such as rice straw, rice husk, wheat, banana leaves, etc., and can be cultivated on large variety of substrates which contain lignin, cellulose and hemicelluose. Mushroom mycelia have the capability to bioconvert the lignocellulosic substances effectively and can colonize on various residues as its substrates. This ability of the mushroom makes them easy to be cultivated using agro- and industrial wastes ${ }^{(3,4)}$.

Due to rapid industrialization worldwide, millions of tons of wastes are being generated and are usually disposed by means of incinerations, land application and land filling. Based on 2018 data, the Philippines is the third largest generator of solid waste per year among Southeast Asian countries and by the end of 2020, 16.6 million metric tons of solid waste are expected to be produced by the Filipinos which is equivalent to 58.2 million cubic meters ${ }^{(5)}$. The methods of wastes disposal have adverse effect, not only to the environment but also to the health of the people. Hence, instead of throwing away these wastes and continue to pollute the environment, this can be biorenewed and can be converted to their useful form by turning those into highvalued organic biomaterials such as substrates in growing nutritious and medically important mushrooms ${ }^{(6)}$. Traditionally, mushrooms are grown in rural areas where there is abundant supply of agricultural wastes such as saw dust, rice hull, rice husk, coconut coir, banana leaves, cotton stalks, soybean straw, pigeon pea stalks and leaves, wheat straw, etc., along or in combination. But its potential to grow in various substrates rich in lignocellulosic substances signifies its possibility to become a good source of food and livelihood in any kind of environment ${ }^{(7)}$.

The above conditions call for search of certain alternative materials which should be available in sufficient quality throughout the year at a relatively cheaper price, particularly in the urban place like Manila. Thus, this research project explores the effective substrate or substrate combinations for the cultivation of $P$. djamor, P. sajor caju and P. florida, using various urban wastes present at the Polytechnic University of the Philippines campus such as used white paper, banana peels and leaf litters.

\section{Materials and Methods}

\subsection{Study site}

Mushroom cultivation, composting of substrates, bagging and sterilization of the substrates were performed at the Institute for Science and Technology Research (ISTR) Laboratory.

\subsection{Collection and preparation of materials}

Mother cultures of Pleurotus djamor, P. sajor-caju, and P. florida purchased from the Bureau of Plant and Industry Mushroom Laboratory were sub-cultured on potato dextrose agar (PDA) to prepare ten (10) subcultures of the mushroom per species. Mycelial growth for each species was further replicated in the spawn made from sorghum grains.

\subsection{Composting of substrates}

Three urban wastes were used as mushroom substrates for this study: used paper (UP); banana peels (BP); and leaf litters (LL). The Sawdust (S) was used to serve as controlled treatment.

White used paper wastes were obtained from the offices inside the PUP campus. Fifty kilograms of the collected paper were shredded into small pieces and soaked in fresh water containing $11 / 2$ kilograms gypsum $\left(\mathrm{CaSO}_{4} \cdot 2 \mathrm{H}_{2} \mathrm{O}\right)$ and 500 grams potassium chloride $(\mathrm{KCl})$. The mixture was left for three weeks with occasional mixing allowing the paper to absorb the water and salts. Composted papers were manually squeezed by hand, leaving at least $85 \%$ moisture.

Fresh banana peels were obtained from the banana cue vendors along the vicinity of Pureza Street and Teresa Street in Sta. Mesa, Manila. Fifty kilograms of the chopped fresh peelings were soaked in water containing calcium carbonate sprinkled with rice bran. The mixed substrate was composted in a large container for a period of 21 days.

Leaf litters, Mangifera indica, Terminalia cattapa, Switenia mahogany, Bambusa vulgaris, Eucalyptus globulus and Ficus religiosa each weighing $3.5 \mathrm{~kg}$ were collected at the vicinity of the campus. These were fragmented into small pieces (1-3 $\mathrm{cm})$, mixed and soaked in water containing rice bran, calcium carbonate and gypsum. The mixture was composted on a large drum for a period of 21 days.

The sawdust medium with $77.5 \%$ sawdust, $20 \%$ rice bran, $1 \%$ sugar, $1 \%$ gypsum, $0.5 \%$ lime and $120 \%-150 \%$ water was adopted generally. Twenty kilograms sawdust was soaked in water containing $350 \mathrm{~g}$ sugar, $7 \mathrm{~kg}$ rice bran, $350 \mathrm{~g}$ gypsum, and $175 \mathrm{~g}$ lime. 


\subsection{Bagging and sterilization of substrates}

The substrates and their various combinations with sawdust were prepared with the addition of 50 grams of rice bran and 10 grams of sugar. Each substrate and substrate combinations were referred to as treatment and were prepared in three sets for P. djamor, P. sajor caju and P. florida as shown in Table 1. Each 1 kilogram of substrate and substrate combinations was added with calamansi extract to adjust the $\mathrm{pH}$ to $5.6-6.0^{(8,9)}$ maintaining enough water to have at least $65 \%$ moisture content. Prepared substrates were packed tightly in polypropylene bags sealed with PVC pipe ring tightened by rubber band and plugged tightly by cotton plug. Fruiting bag for each substrate and substrate combinations was prepared in three replicates. Fruiting bags were autoclaved for 1 hour at $121^{\circ} \mathrm{C}$ and 15 psi and allowed to cool down 24 hours.

Table 1. Percentage content of the substrates per treatment for P. sajor caju, P. florida and P. djamor

\begin{tabular}{lllll}
\hline \multirow{2}{*}{ Treatment } & \multicolumn{4}{c}{ Percentage Mixture (\%) } \\
\cline { 2 - 5 } & Sawdust (S) & Used Paper (UP) & Banana Peel (BP) & 0 \\
\hline S100 & 100 & 0 & 0 & 0 \\
UP100 & 100 & 0 & 0 & 0 \\
UP75 & 25 & 75 & 0 & 0 \\
UP50 & 50 & 50 & 0 & 0 \\
UP25 & 75 & 25 & 0 & 0 \\
BP100 & 100 & 0 & 0 & 0 \\
BP75 & 25 & 0 & 75 & 0 \\
BP50 & 50 & 0 & 50 & 0 \\
BP25 & 75 & 0 & 25 & 0 \\
LL100 & 100 & 0 & 0 & 75 \\
LL75 & 25 & 0 & 0 & 50 \\
LL50 & 50 & 0 & 0 & 25 \\
LL25 & 75 & 0 & 0 & \\
\hline
\end{tabular}

Legend: S - sawdust;UP - used paper; BP - banana peel; LL - leaf litter.

\subsection{Seeding spawn of the substrates and incubation of the fruiting bags}

Each of the fruiting bags was aseptically inoculated with one teaspoonful of the mother grains containing the mushroom mycelia. Inoculated fruiting bags were kept in the isolation room of Institute for Science and Technology Research Laboratory allowing the completion of the whitish mycelial growth ${ }^{(10)}$. Relative humidity of around $80 \%$ to $85 \%$ was maintained in the room while temperature was monitored daily assuring that the room was kept cool and moistened.

\subsection{Culture condition for fructification of Basidiocarp}

After mycelia have completely colonized the substrate, the bags were then opened to trigger fructification. Water spraying was done thrice a day until the mushrooms were matured enough to be harvested. The temperature between 26 to 28 degrees Celsius was monitored daily. High relative humidity of 80 to $85 \%$ and proper ventilation was maintained for the development of fruiting body with the use of hygrometer ${ }^{(8)}$.

\subsection{Data collection and statistical analysis}

The experiment was laid out in Completely Randomized Design (CRD) with thirteen (13) treatments including the control with three (3) replicates each. First mushroom flush was harvested and used for data analysis.

The percentage mycelial colonization (spawn running) was recorded in terms of the number of days. The number of fruiting bodies (FB) and fresh weight of the mushroom per treatment were obtained immediately after the first harvest. The diameter of expanded caps (PD) and length of stalks (SL) of the harvested mushrooms were measured using digital Vernier caliper. Total weight (TW) of the fruiting bodies harvested from the first mushroom flush was measured as total yield of mushroom. Size of the mushrooms (SM) was calculated by total weight of the mushroom / number of fruiting bodies harvested. The biological 
efficiency (BE) of the different substrates used was calculated by following the formula made by Chang et al. ${ }^{(11)}$ :

$$
\text { Bio } \log \text { ical Yield }=\frac{\text { Fresh weight }(\mathrm{g}) \text { of the mushroom harvested }}{\text { Dry weight }(\mathrm{g}) \text { of the substrate } X 100}
$$

Data obtained were analyzed by one-way analysis of variance and means were compared by Shapiro-wilk normality tests and Levenes test by R studio. Differences were considered significant at $\mathrm{p}<0-.05$.

\section{Results and Discussion}

The urban wastes used as substrates in this study such as: used paper (UP), banana peels (BP) and leaf litters (LL) and the sawdust (S) as controlled treatment, contain cellulose, hemicellulose and lignin. Although urban wastes are resistant to degradation because of these components, Basidiomycetes like Pleurotus species can degrade those lignin and cellulose ${ }^{(3)}$ with the aid of enzymes which contain carbohydrate and polyphenol (oxides). Fungal mycelium excretes extensive enzymes complexes which can directly attack and degrade these components. They therefore used these wastes as source of nutrients for their growth and proliferation ${ }^{(12)}$. The addition of supplements to the basic organic substrates also helps in increasing the yield of the mushroom fruiting bodies.

Mycelial growth of P. djamor, P. sajor-caju, and P. florida were observed on different treatments (Figures 1, 2 and 3) after a week of inoculation. Data showed that the beginning of degradation of the substrates by the test fungi were similar to a study ${ }^{(13)}$ as demonstrated in the cultivation of $P$. sajor caju. Results revealed that the number of days taken to fully colonize the different substrates and substrate combinations differ from one another which ranges from 21 to 35 days. Shapiro-Wilk normality test showed that the percentage of mycelium run per week were significantly different in all treatments by species at $\mathrm{p} \leq 0.05$. Rapid mycelial colonization was observed in UP100 which was fully completed on the $3^{\text {rd }}$ week for $P$. florida and $P$. sajor caju, and nearly $4^{\text {th }}$ week for $P$. djamor. Slowest mycelial colonization was demonstrated by BP75 for P. florida and P. djamor while LL25 for P. sajor caju which completed only on the $5^{\text {th }}$ week.

Chang and Miles ${ }^{(14)}$ demonstrated that the performance of the mycelium should be checked continuously, although not all degenerative symptoms can be detected in the mycelium stage. The degenerative symptoms that are commonly detected are sectors of slow growth, mycelium that is thin and with weak appearance, or mycelium that is matted or fluffy but has normal growth rate. Such variation in mycelial growth could be due to the differences in nutrient composition of the different substrates and substrate combinations ${ }^{(15)}$. It is notable that Pleurotus mycelia easily colonized the substrates containing $100 \%$ used paper. On the other hand, the absence of mycelial growth observed from $100 \%$ banana peels and $100 \%$ leaf litters could be due to the deficiency of nutritional requirement for the growth of the mycelia into the substrate. The results are in accordance with those reported by a study ${ }^{(16)}$ that the duration of mycelia invasion differs depending on the type of substrate used. A study ${ }^{(12)}$ supported that a slow growing mycelium needs more time for colonization and tend to carry virus particles that usually give lower yield and these types of mycelia should be discarded. A study ${ }^{(17)}$ also reported that mushroom mycelia growth and primordial development is dependent on C: $\mathrm{N}$ ratio. The physical nature of leaf litters has a high C: $\mathrm{N}$ ratio that possibly not suitable for the Pleurotus spp.

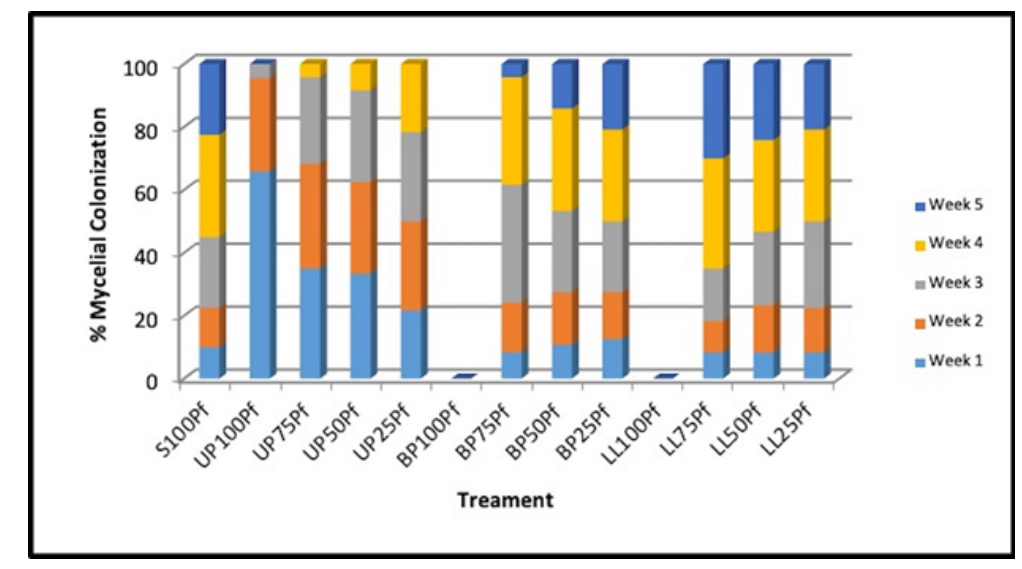

Fig 1. Percentage mycelial colonization of florida in the different substrates. Legend: S - sawdust; UP - used paper; BP - banana peel; LL - leaf litter 


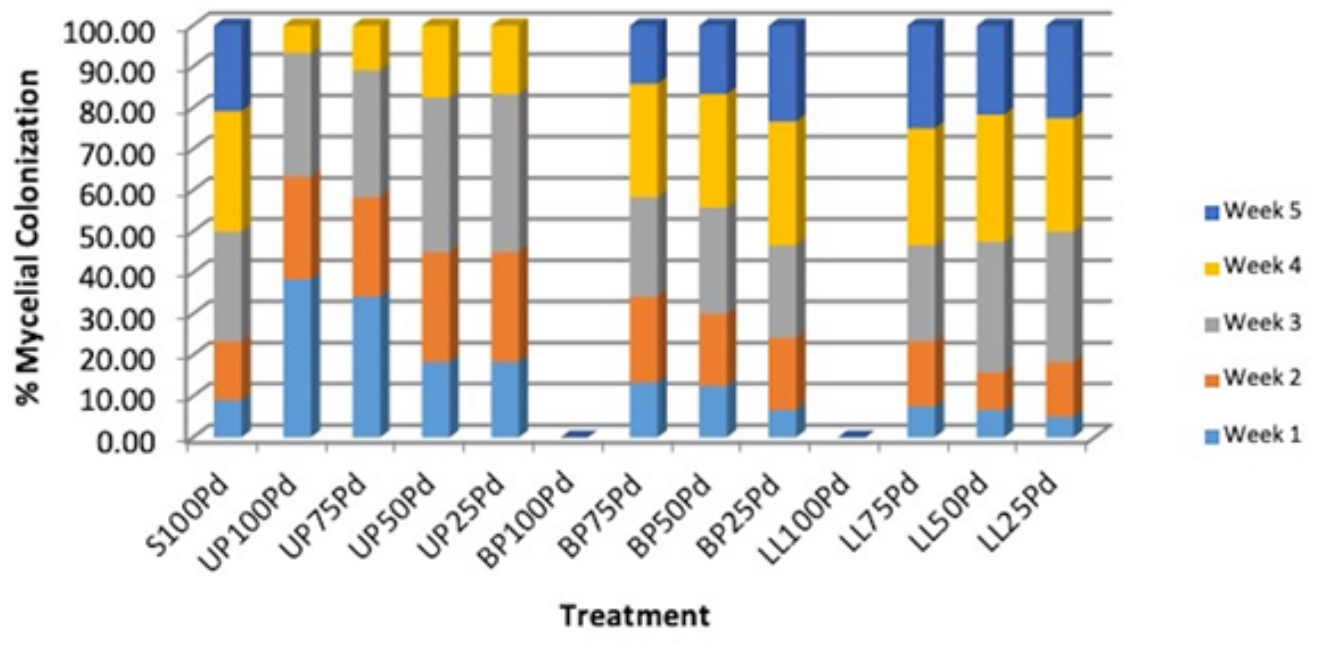

Fig 2. Percentage mycelial colonization of $P$. djamor in the different substrates. Legend: S - sawdust; UP - used paper; BP - banana peel; LL leaf litter

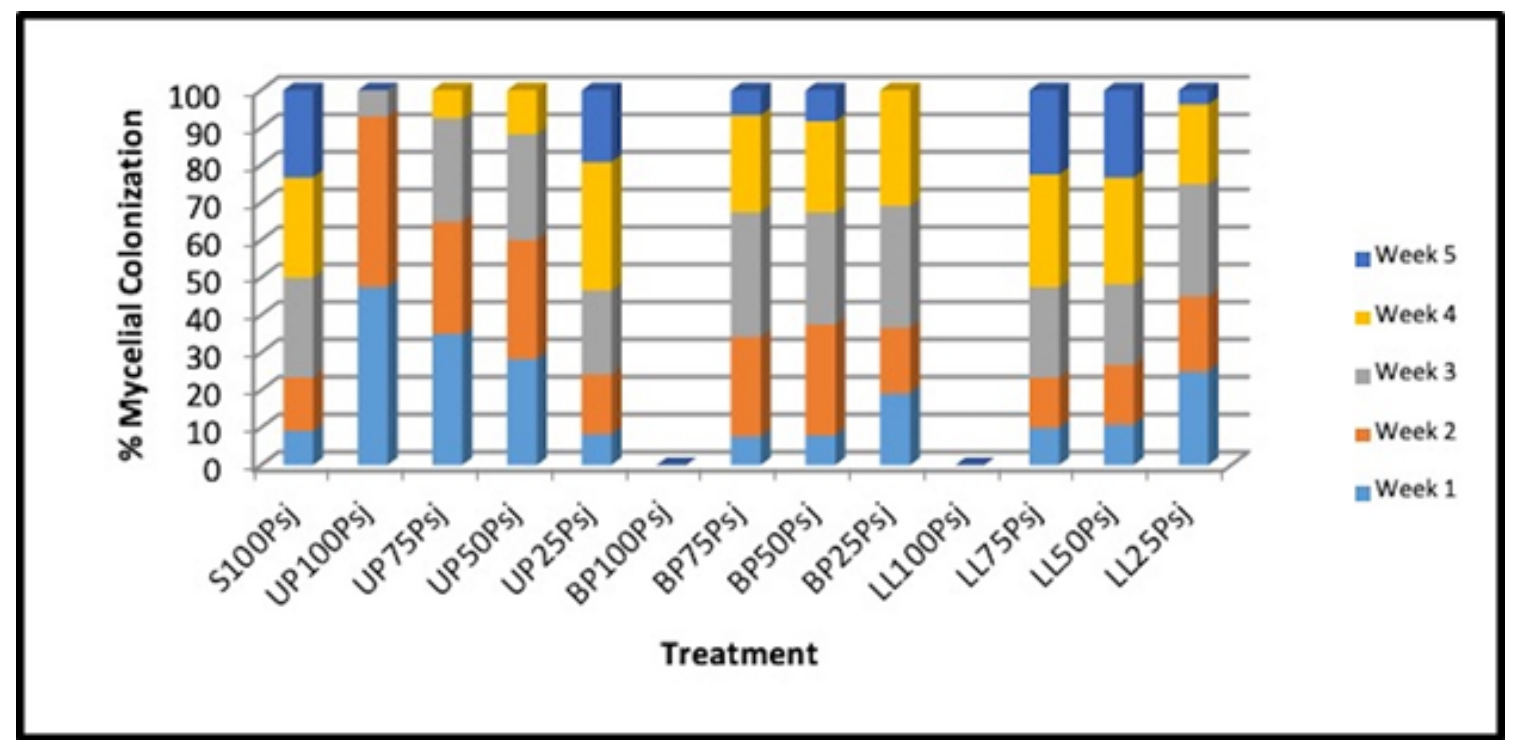

Fig 3. Percentage mycelial colonization of $P$. sajor caju in the different substrates. Legend: S - sawdust; UP - used paper; BP - banana peel; LL - leaf litter

\subsection{Mushroom growth and yield performance}

Determining the growth, fruiting and yield of mushroom produced on a particular substrate is very essential in identifying the ability of the mushroom to produce specific enzymes essential in the degradation of the major components of the substrates, and therefore absorb it as food. The number of well-developed fruiting bodies, cap diameter, stalks length and total mushroom produced for each substrate for P. djamor, P. sajor caju and P. florida are shown in Tables 2, 3 and 4, respectively. The performance of the Pleurotus fungi grown in different urban substrates with respect to stalk length and pileus diameter is dependent on the structure, compactness, and physical properties of the substrate which in turn dependent on the type of urban wastes used in preparing the substrates. The substrate with the higher moisture retaining capacity performs better than those with lower moisture retaining capacity. 
Table 2. Mean number of fruiting bodies, pileus diameter, stalk length and total weight of the harvested $P$. djamor in the different substrates.

\begin{tabular}{lllll}
\hline Substrates & Fruiting body (number) & Pileus diam. $(\mathrm{cm})$ & Stalk length $(\mathrm{cm})$ & Total weight $(\mathrm{g})$ \\
\hline S100 & $4.00 \pm 1.59$ & $71.04 \pm 9.48$ & $27.00 \pm 9.87$ & $66.00 \pm 6.43$ \\
UP100 & $19.33 \pm 1.59$ & $47.93 \pm 9.48$ & $36.03 \pm 9.87$ & $90.77 \pm 6.43$ \\
UP75 & $4.00 \pm 1.59$ & $63.42 \pm 9.48$ & $35.99 \pm 9.87$ & $32.00 \pm 6.43$ \\
UP50 & $3.33 \pm 1.59$ & $57.71 \pm 9.48$ & $29.27 \pm 9.87$ & $42.33 \pm 6.43$ \\
UP25 & $8.00 \pm 1.59$ & $20.93 \pm 9.48$ & $19.75 \pm 9.87$ & $20.56 \pm 6.43$ \\
BP100 & 0 & 0 & 0 & 0 \\
BP75 & $3.67 \pm 1.59$ & $64.24 \pm 9.48$ & $42.29 \pm 9.87$ & $26.02 \pm 6.43$ \\
BP50 & $3.67 \pm 1.59$ & $49.70 \pm 9.48$ & $41.54 \pm 9.87$ & $41.38 \pm 6.43$ \\
BP25 & $4.00 \pm 1.59$ & $56.36 \pm 9.48$ & $38.29 \pm 9.87$ & $28.32 \pm 6.43$ \\
LL100 & 0 & 0 & 0 & 0 \\
LL75 & $2.00 \pm 1.59$ & $81.86 \pm 9.48$ & $58.51 \pm 9.87$ & $21.28 \pm 6.43$ \\
LL50 & $3.67 \pm 1.59$ & $54.26 \pm 9.48$ & $39.32 \pm 9.87$ & $19.01 \pm 6.43$ \\
LL25 & $3.33 \pm 1.59$ & $86.86 \pm 9.48$ & $68.35 \pm 9.87$ & $27.48 \pm 6.43$ \\
\hline
\end{tabular}

Legend: S- sawdust; UP- used paper; BP- banana peel; LL- leaf litter.

Table 3. Mean number of fruiting bodies, pileus diameter, stalk length, and total weight of the harvested $P$. sajor caju in the different substrates.

\begin{tabular}{lllll}
\hline Substrates & Fruiting body (number) & Pileus diam. $(\mathrm{cm})$ & Stalk length $(\mathrm{cm})$ & Total weight $(\mathrm{g})$ \\
\hline S100 & $16.00 \pm 2.93$ & $40.79 \pm 12.20$ & $27.13 \pm 7.01$ & $60.34 \pm 8.36$ \\
UP100 & $20.67 \pm 2.93$ & $57.43 \pm 12.20$ & $29.18 \pm 7.01$ & $112.22 \pm 8.36$ \\
UP75 & $22.33 \pm 2.93$ & $48.77 \pm 12.20$ & $31.49 \pm 7.01$ & $132.82 \pm 8.36$ \\
UP50 & $13.33 \pm 2.93$ & $49.89 \pm 12.20$ & $37.34 \pm 7.01$ & $107.85 \pm 8.36$ \\
UP25 & $8.00 \pm 2.93$ & $41.16 \pm 12.20$ & $28.44 \pm 7.01$ & $40.57 \pm 8.36$ \\
BP100 & 0 & 0 & 0 & 0 \\
BP75 & $6.00 \pm 2.93$ & $48.03 \pm 12.20$ & $38.31 \pm 7.01$ & $52.52 \pm 8.36$ \\
BP50 & $7.67 \pm 2.93$ & $35.56 \pm 12.20$ & $23.47 \pm 7.01$ & $62.36 \pm 8.36$ \\
BP25 & $8.00 \pm 2.93$ & $25.82 \pm 12.20$ & $23.47 \pm 7.01$ & $40.26 \pm 8.36$ \\
LL100 & 0 & 0 & 0 & 0 \\
LL75 & $3.00 \pm 2.93$ & $91.52 \pm 12.20$ & $65.75 \pm 7.01$ & $38.35 \pm 8.36$ \\
LL50 & $2.00 \pm 2.93$ & $92.37 \pm 12.20$ & $70.59 \pm 7.01$ & $18.26 \pm 8.36$ \\
LL25 & $2.67 \pm 2.93$ & $92.40 \pm 12.20$ & $65.52 \pm 7.01$ & $22.69 \pm 8.36$ \\
\hline
\end{tabular}

Legend: S- sawdust; UP- used paper; BP- banana peel; LL- leaf litter

Table 4. Mean number of fruiting bodies, pileus diameter, stalk length, and total weight of the harvested $P$. florida in the different substrates.

\begin{tabular}{lllll}
\hline Substrates & Fruiting body (number) & Pileus diam. $(\mathrm{cm})$ & Stalk length $(\mathrm{cm})$ & Total weight $(\mathrm{g})$ \\
\hline S100 & $9.00 \pm 1.66$ & $57.02 \pm 7.53$ & $35.04 \pm 5.05$ & $54.42 \pm 7.71$ \\
UP100 & $7.67 \pm 1.66$ & $56.61 \pm 7.53$ & $47.53 \pm 5.05$ & $40.00 \pm 7.71$ \\
UP75 & $6.67 \pm 1.66$ & $69.87 \pm 7.53$ & $53.63 \pm 5.05$ & $61.81 \pm 7.71$ \\
UP50 & $8.67 \pm 1.66$ & $41.87 \pm 7.53$ & $36.74 \pm 5.05$ & $44.30 \pm 7.71$ \\
UP25 & $8.00 \pm 1.66$ & $37.08 \pm 7.53$ & $26.32 \pm 5.05$ & $37.00 \pm 7.71$ \\
BP100 & 0 & 0 & 0 & 0 \\
BP75 & $6.00 \pm 1.66$ & $39.66 \pm 7.53$ & $30.39 \pm 5.05$ & $49.86 \pm 7.71$ \\
BP50 & $4.33 \pm 1.66$ & $33.36 \pm 7.53$ & $22.32 \pm 5.05$ & $47.94 \pm 7.71$ \\
BP25 & $13.00 \pm 1.66$ & $47.66 \pm 7.53$ & $32.02 \pm 5.05$ & $75.51 \pm 7.71$ \\
LL100 & 0 & 0 & 0 & 0 \\
LL75 & $3.33 \pm 1.66$ & $83.51 \pm 7.53$ & $60.69 \pm 5.05$ & $34.94 \pm 7.71$ \\
LL50 & $2.33 \pm 1.66$ & $64.66 \pm 7.53$ & $43.08 \pm 5.05$ & $15.81 \pm 7.71$ \\
LL25 & $4.00 \pm 1.66$ & $55.90 \pm 7.53$ & $45.61 \pm 5.05$ & $21.37 \pm 7.71$ \\
\hline
\end{tabular}

Legend: S- sawdust; UP- used paper; BP- banana peel; LL- leaf litter

\subsection{Number of fruiting bodies produced on each substrate and substrate combinations}

When the mycelium has fully colonized the substrate, the fungus is ready for fruiting. Fruiting body is the edible part of the mushroom that usually varies in size, shape and coloration and aid in the identification of the specific species. For this study, 
the number of effective fruiting body significantly varied $\mathrm{p} \leq 0.05$ in all the treatments in all species. The highest number of effective fruiting body was obtained from BP25 for P. florida (13.00 \pm 1.72 ), UP100 for P. djamor (19.33 \pm 1.58 ) and UP75 for $P$. sajor caju (22.33 \pm 2.93$)$. The lowest number was obtained from LL75 for $P$. djamor (2.00 \pm 1.58 ) and LL50 for both $P$. florida $(2.33 \pm 1.72)$ and $P$. sajor caju $(2.00 \pm 2.93)$. In the research ${ }^{(15)}$ it was found that days for the formation fruiting bodies were increased when $P$. ostreatus was cultivated on leaves compared to the other substrates used i.e., wheat straw, saw dust and their mixtures. The average number of fruiting bodies yielded from three flushes and biological efficiency were at its lowest values when $P$. ostreatus was cultivated on leaves compared to other substrates. The formation and growth of fruiting bodies are sensitive to environmental conditions, such as temperature, humidity, carbon dioxide concentration, and moisture content in the mushroom substrate. Improper balance of these factors can induce fruiting body deformations ${ }^{(18)}$.

\subsection{Pileus diameter and stalk length}

Pileus diameters were immediately recorded after each mushroom harvest from different substrates and substrate combinations. Levenes test for $P$. sajor caju and $P$. djamor and Shapiro-wilk normality test for $P$. florida, showed that the results significantly varied $\mathrm{p} \leq 0.05$ in all the treatments in all species. The biggest pileus diameter that was recorded for $P$. djamor $(86.86 \pm 9.47 \mathrm{~mm})$ and $P$. sajor caju $(92.40 \pm 12.20 \mathrm{~mm})$ was both from LL25 while $P$. florida $(83.51 \pm 7.90 \mathrm{~mm})$ was from LL75. The smallest pileus diameter for $P$. djamor $(20.93 \pm 9.48 \mathrm{~mm})$ was recorded from UP25, $P$. sajor caju $(25.82 \pm 12.20 \mathrm{~mm})$ was from BP25 and $P$. florida $(33.36 \pm 7.90 \mathrm{~mm})$ was from BP50 of $14.12 \mathrm{~mm}$ was obtained from $50 \%$ banana peels $+50 \%$ sawdust with $P$. djamor. A study ${ }^{(19)}$ reported that oyster mushroom has a cap spanning diameter of 5 to $25 \mathrm{~cm}$ at maturity which is slightly small when compared to the harvested Pleurotus from the study. Another research ${ }^{(20)}$ on the other hand, found no significant differences with the cap diameter, stipe diameter, or stipe length with his study.

Light usually influences color of the fruiting body and the length of the stipe. A research ${ }^{(18)}$ demonstrated that mushrooms with elongated stipe and light-colored cap are produced under poor light, while mushroom with short stipe and dark-colored cap are produced under excessive light. The longest stalk that recorded for $P$. djamor $(68.35 \pm 9.87 \mathrm{~mm})$ was from LL25, P. sajor caju $(70.58 \pm 7.01 \mathrm{~mm})$ was from LL50 while $P$. florida $(60.69 \pm 9.47 \mathrm{~mm})$ was from LL75. The shortest stalk recorded for $P$. djamor $(19.75 \pm 9.87 \mathrm{~mm})$ was recorded from UP25, P. sajor caju $(23.47 \pm 12.20 \mathrm{~mm})$ was from BP25 and P. florida $(22.32 \pm 5.46 \mathrm{~mm})$ was from BP50.

In a research ${ }^{(21)}$ it was found that the longest stalk were the oyster mushroom grown on bean straw, followed by finger millet straw, maize cobs, banana fiber and the shortest were grown on sawdust. Relatively small pileus diameter and long stalk length are undesirable characteristics of mushroom in terms of its marketable quality. Likewise, large pileus with long stalk doesn't necessarily mean better mushroom yield. These characteristics are always taken into consideration when choosing the proper substrate used for cultivation. Environmental conditions as well as supplementation of substrates with various additives including nitrogen sources have been reported to improve growth, yield and quality of mushrooms ${ }^{(22-24)}$. In this study, short mushroom stalk length and enlarge mushroom cap diameter might be due to the supplement of rice bran and urea to white used paper. These supplements can change the physical properties and $\mathrm{C} / \mathrm{N}$ ratio of each substrate that may increase marketable quality of Pleurotus.

\subsection{Total yield of Mushroom produced in first flush}

The productivity of oyster mushroom per unit time is very high as compared to all other cultivated mushrooms. The biggest yield for $P$. djamor $(90.77 \pm 6.43 \mathrm{~g}$ ) was recorded from UP100, for P. sajor caju (132.82 \pm 8.36$)$ was from UP75 and for P. florida (75.51 \pm 8.31 ) was from BP25. The lowest yield for P. djamor (19.01 $\pm 8.36 \mathrm{~g})$, P. sajor caju (18.26 \pm 8.36$)$ and $P$. florida $(15.81 \pm 8.31)$ were all recorded from LL50. Moreover, Shapiro-wilk normality test showed that all treatments showed significant differences in all species at $\mathrm{p} \leq 0.05$. Same results were found in a study ${ }^{(25)}$ that the best results from suitable substrates for cultivation of mushroom was from wastepaper. Such may be due to high lignin content of paper which possibly contributed to the high mushroom yield. The low yield from leaf litter substrates may be due to carbon to nitrogen imbalance ${ }^{(26)}$. The harvest indices of mushroom stalk length and pileus diameter were similarly affected as mushroom yield by the different substrate combinations ${ }^{(27)}$.

\subsection{Biological Efficiency of Substrates Used}

The biological efficiency of the three Pleurotus species investigated differed in accordance with the substrate or substrate combinations tested. The highest biological efficiency for $P$. djamor (35.30 \pm 4.00 ) was recorded from UP100, for $P$. sajor caju $(52.38 \pm 4.94)$ was from UP75 and for P. florida (19.94 \pm 2.29$)$ was from BP25. The lowest biological efficiency obtained for

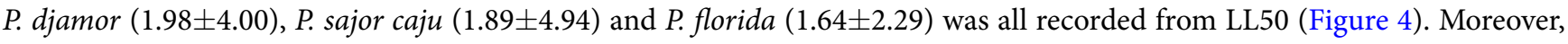


Shapiro-wilk normality test showed that there is a significant difference between the biological efficiency between each substrate used in the cultivation of $P$. sajor caju, $P$. florida and $P$. djamor at $\mathrm{p} \leq 0.05$. Several studies ${ }^{(28,29)}$ demonstrated similar results.
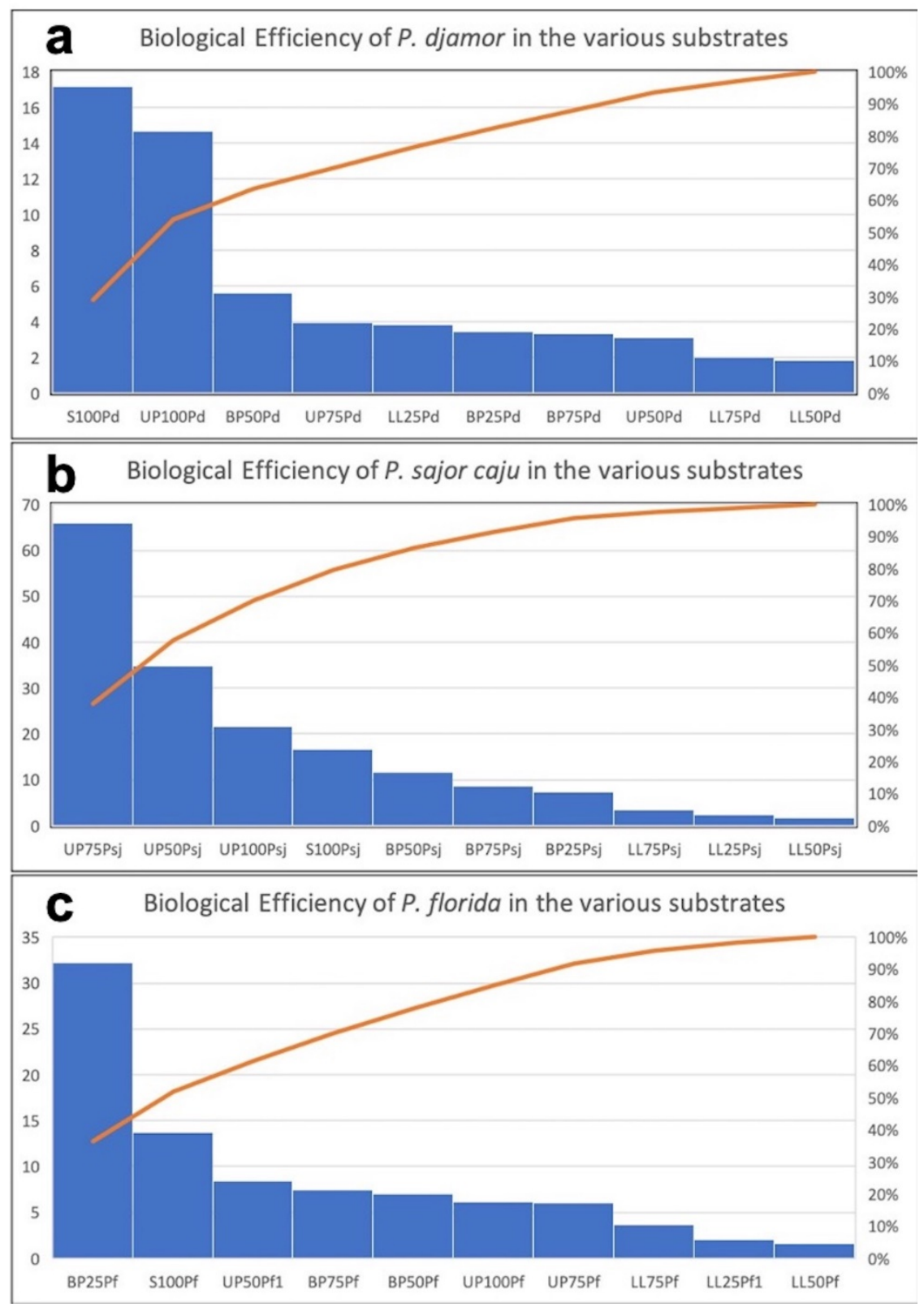

Fig 4. Mean biological efficiency of each substrates in the Pleurotus species: a) P. djamor; b) P. sajor caju; and c) P. florida.

Notably, the substrate where the highest and the lowest mushroom yield was obtained for P. djamor, P. florida and P. sajor caju was the same substrate where the highest and lowest percentage biological efficiency was computed. Relevant studies ${ }^{(30,31)}$ showed that the higher the mushroom yield and biological efficiency correspond to the mycelia growth, colonization period and harvest period. These indicate that the three mushrooms tested from this study, $P$. djamor, $P$. florida and $P$. sajor caju, differs in term of their nutritional and environmental condition requirements. Related studies ${ }^{(32)}$ demonstrated that variation in the growth parameters of the mushroom species might be attributed to the effect of ecological factors and nutrition of the substrate. Furthermore, results revealed that those substrates (substrates containing leaf litters) where large cap and long stalk were obtained were not the same substrates where the large yield and high biological efficiency were obtained (Figure 5). This implies that obtaining good harvest from a particular substrate does not necessarily depend on the size of mushroom pileus 
and stalk. It should also be noted that all mushroom samples used in the study did not proliferated in the BP100 and LL100, which indicate that these substrates probably lack nutritional requirements needed by the mushroom to grow.

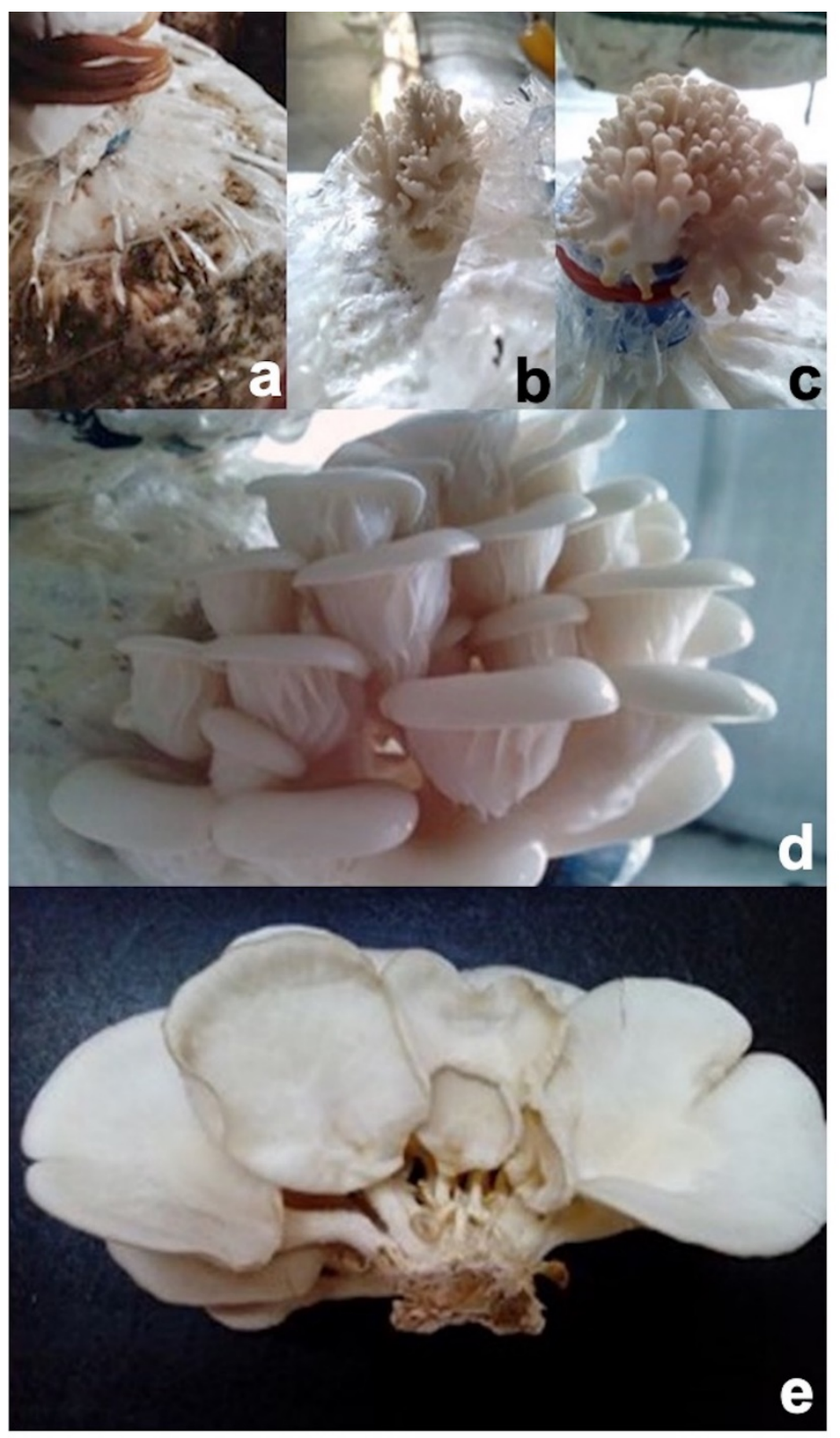

Fig 5. Stages of Pleurotus florida's growth on UP100. (a) mycelial colonization, (b-c) primordial formation, (d) mushroom on $100 \%$ white used paper and (e) harvested P. florida.

\section{Conclusion and Recommendations}

Pleurotus florida, P. djamor and P. sajor caju have the capability to grow on urban wastes rich in lignocellulosic substances such as used papers, banana peels and leaf litters. The growth and yield of performance of $P$. djamor, P. florida and $P$. sajor cajus on different substrates and substrate combinations varies significantly with one another. Moreover, among the substrates used in the study, the best substrates to cultivate P. djamor is $100 \%$ used paper (UP100), for P. sajor-caju is $75 \%$ white used paper $+25 \%$ sawdust (UP75), and for $P$. florida is $25 \%$ banana peel $+75 \%$ sawdust (BP25). BP100 and LL100 must probably need additional 
nutritional supplements or must be mixed with other substrates to become desirable substrates for Pleurotus cultivation.

Mushroom growing in the urban place like Manila, must be encouraged. Aside from the fact that mushrooms are essential source of nutritious food and medically important metabolites, mushroom cultivation is a potent valuable source of livelihood. A technology of using other lignocellulosic urban wastes in mushroom cultivation must be established and must be properly disseminated to communities to extend assistance to people to put up an income generating program. Such move will not only help people in the community but will also help lessen wastes into the environment.

Limitations: The heavy metal contents of the harvested mushrooms were not subjected to to analysis as it can affect the food quality and generally microbes are known to accumulate heavy metals from the substrate; in a case like the urban wastes, this factor must be monitored for edible use.

\section{Acknowledgements}

The researchers would like to acknowledge the Polytechnic University of the Philippines for the provision of institutional fund for the conduct of this research. Special thank is given to Abigail Mae Jambaro for the assistance extended during the implementation of the project.

\section{References}

1) Patil SS. Cultivation of Pleurotus sajor caju on different agro wastes. Science Research Reporter. 2012;2(3):225-228. Available from: https://jsrr.net/Vol. 2\%20No.3/10\%20Patil\%2043-46.pdf.

2) Ramos IR. Health and Nutritional Properties of Mushroom. Technological Centre for Research on Mushroom (CTICH), Spain and European Group of Mushroom Growers, France (GEPC). 2015. Available from: https://leden.inagro.be/DNN_DropZone/Publicaties/2614/ Healthandnutritionalpropertiesofmushrooms_engelsebrochure.pdf.

3) Ritota M, Manzi P. Pleurotus spp. Cultivation on Different Agri-Food By-Products: Example of Biotechnological Application. Sustainability. 2019;11(18):5049-5049. Available from: https://dx.doi.org/10.3390/su11185049.

4) Girmay Z, Gorems W, Birhanu G, Zewdie S. Growth and yield performance of Pleurotus ostreatus (Jacq. Fr.) Kumm (oyster mushroom) on different substrates. AMB Express. 2016;6. Available from: https://dx.doi.org/10.1186/s13568-016-0265-1.

5) Romero P. Philippines Facing Garbage Crisis; 16.6 Million Metric Tons of Waste This Year Can Fill 99 Philippine Arenas. The Star Philippines. 2020. Available from: https://www.onenews.ph/phl-facing-garbage-crisis-16-6-million-metric-tons- of-waste-this-year-can-fill-99-philippine-arenas.

6) Sözbir GD, Bektas I, Zulkadir A. Lignocellulosic Wastes Used for the Cultivation of Pleurotus ostreatus Mushrooms: Effects on Productivity. BioResources. 2015;10(3):4686-4693. Available from: https://dx.doi.org/10.15376/biores.10.3.4686-4693.

7) Mane VP, Patil SS, Syed AA, Baig MMV. Bioconversion of low quality lignocellulosic agricultural waste into edible protein by Pleurotus sajor-caju (Fr.) singer. Journal of Zhejiang University SCIENCE B. 2007;8(10):745-751. Available from: https://dx.doi.org/10.1631/jzus.2007.b0745.

8) Custodio JD. Mushroom growers' handbook 1: substrate - coco lumber sawdust. Philippines. Bataan State College. 2004. Available from: http: //www.fungifun.org/mushworld/Oyster-Mushroom-Cultivation/mushroom-growers-handbook-1-mushworld-com-chapter-5-2.pdf.

9) Gibriel AY, Ahmed M, Rasmy N, Rizk I, Abdelrehem NS. Cultivation of oyster mushrooms (Pleurotus spp.): Evaluations of different media and organic substrates. In: Mushroom biology and Mushroom Products Proceedings of the 2nd International Conference. 1996;p. 415-421. Available from: https://agris.fao.org/agris-search/search.do?recordID=US201302878099.

10) Sturion GL, Otterer M. Composica Quimica de Cogumelos comestivals (Pleurotus sp.) originados de cultivos em differentes substrates. Ciencia e Tecnologia de Alimentos. 1995;15(2):189-193. Available from: http://ve.scielo.org/scielo.php?pid=S0004-06222000000100015\&script=sci_abstract\&tlng= en.

11) Chang ST, Lau OW, Cho KY. The cultivation and nutritional value of Pleurotus sajor-caju. European Journal of Applied Microbiology and Biotechnology. 1981;12(1):58-62. Available from: https://dx.doi.org/10.1007/bf00508120.

12) Amuneke EH, Dike KS, Ogbulie J. Cultivation of Pleurotus ostreatus: an edible mushroom from agro base waste production. J Microbiol Biotechnol. 2011;1:1-14. Available from: https://www.cabdirect.org/cabdirect/abstract/20133073692.

13) Moda EM, Horii J, Spoto MHF. Edible mushroom Pleurotus sajor-caju production on washed and supplemented sugarcane bagasse. Scientia Agricola. 2005;62(2):127-132. Available from: https://dx.doi.org/10.1590/s0103-90162005000200006.

14) Chang ST, Miles PG. Mushrooms: Cultivation, Nutritional value, Medicinal effect, and Environmental Impact. 2nd ed. Boca Raton, Fla, USA. CRC Press. 2008.

15) ZAS, MA, Ishtiaq MCH. Comparative Study on Cultivation and Yield Performance of Oyster Mushroom (Pleurotus ostreatus) on Different Substrates (Wheat Straw, Leaves, Saw Dust). Pakistan Journal of Nutrition. 2004;3(3):158-160. Available from: https://dx.doi.org/10.3923/pjn.2004.158.160.

16) Stanley OH, Awi-Waadu GD. Effect of Substrates of Spawn Production on Mycelial Growth of Oyster Mushroom Species. Research Journal of Applied Sciences. 2010;5(3):161-164. Available from: https://dx.doi.org/10.3923/rjasci.2010.161.164.

17) Naraian R, Sahu RK, Kumar S, Garg SK, Singh CS, Kanaujia RS. Influence of different nitrogen rich supplements during cultivation of Pleurotus florida on corn cob substrate. The Environmentalist. 2009;29(1):1-7. Available from: https://dx.doi.org/10.1007/s10669-008-9174-4.

18) Kwon H, Kim SB. Mushroom grower's handbook. 1: Bag cultivation in: Oyster Mushroom Cultivation. Republic of Korea. Mushworld. 2004. Available from: http://www.fungifun.org/mushworld/Oyster-Mushroom-Cultivation/mushroom-growers-handbook-1-mushworld-com-chapter-7-1.pdf.

19) Gunde CN, Cinerman A. Inhibitor content of Pleurotus fruiting bodies. J Exp Mycol. 1995;19(1):1-6. Available from: https://doi.org/10.1006/emyc.1995. 1001.

20) Khattab EAK. Effect of some cultural practices on mushroom production. Egypt. 2000. Available from: https://agris.fao.org/agris-search/search.do? recordID=EG2002000870.

21) Kimenju JW, Odero GOM, Mutitu EW, Wachira PM, Narla RD, Muiru WM. Suitability of Locally Available Substrates for Oyster Mushroom (Pleurotus ostreatus) Cultivation in Kenya. Asian Journal of Plant Sciences. 2009;8(7):510-514. Available from: https://dx.doi.org/10.3923/ajps.2009.510.514. 
22) Royse D. Influence of spawn rate and commercial delayed release nutrient levels on Pleurotus cornucopiae (oyster mushroom) yield, size, and time to production. Applied Microbiology and Biotechnology. 2002;58(4):527-531. Available from: https://dx.doi.org/10.1007/s00253-001-0915-2.

23) Mane VP, Patil SS, Syed AA, Baig MMV. Bioconversion of low quality lignocellulosic agricultural waste into edible protein by Pleurotus sajor-caju (Fr.) singer. Journal of Zhejiang University SCIENCE B. 2007;8(10):745-751. Available from: https://dx.doi.org/10.1631/jzus.2007.b0745.

24) Onyango BO, Palapala VA, Arama PF, Wagai SO, Gichumu BM. Sustainability of selected supplemented substrates for cultivation of Kenyan native wood ear mushrooms (Auricularia auricula). Am J Food Technol. 2011;6:395-403. Available from: https://dx.doi.org/10.3923/ajft.2011.395.403.

25) Sivaprakasam K, Kandaswamy TK. Waste materials for the cultivation of Pleurotus sajor-caju. C F Hort Abstr. 1981;101:178-179.

26) Oei P. Mushroom Cultivation with special emphasis on appropriate techniques for developing countries. Leiden, Netherlands. Tool Publication. 1996. Available from: https://www.nlb.gov.sg/biblio/8683028.

27) Earnshaw DM, Dlamini B, Masarirambi MT. Growth and yield of Oyster mushroom (Pleurotus ostreatus) grown on different substrates amended with varying levels of wheat bran. International Journal of Life Sciences. 2012;1(4):111-117. Available from: http://www.crdeepjournal.org/wp-content/uploads/ 2012/10/Vol-146-IJLS.pdf.

28) Khan SM, Kausar AG, Ali MA. Yield Performance of different strains of oyster mushroom (Pleurotus spp.) on paddy straw in Pakistan. Mush Sci X1 Sydney. 1991;1:675-667.

29) Cedano M, Martmez M, Soto-Velazco C, Guzman-Davalos L. Pleurotus ostreatoroseus (Basidiomycotina, Agaricales) in Mexico and its growth in agroindustrial wastes. Cryptogamic Botany. 1993;3(4):297-302. Available from: https://www.cabdirect.org/cabdirect/abstract/19940311613.

30) Pokhrel CP, Kalyan N, Budathoki U, Yadav RKP. Cultivation of Pleurotus sajor-caju using different agricultural residues. International Journal of Agricultural Policy and Research. 2013;1(2):19-23. Available from: https://journalissues.org/wp-content/uploads/2014/07/Pokhrel-et-al.pdf.

31) Jambaro A, Neri KD, Alvarez LV. Utilization of Selected Urban Wastes as Substrate Solutions in the Growth and Yield Performance of Pleurotus Sajor-Caju (Fr.) Singer (Gray Oyster Mushroom). PUP Journal of Science and Technology. 2014;7(1):28-44. Available from: https://cutt.ly/Gj4WuMO.

32) Sobowale AA, Atoyebi FT, Adenipekun CO. Fungal Incidence and Growth of Two Pleurotus Species on Sawdust of Ceiba pentandra (Linn.) Gaertn and Ficus Mucuso welw (Softwoods). Journal of Plant Pathology \& Microbiology. 2018;09(08). Available from: https://dx.doi.org/10.4172/2157-7471.1000448. 